\title{
ECDC publishes the annual epidemiological report 2012
}

Eurosurveillance editorial team (eurosurveillance@ecdc.europa.eu) ${ }^{1}$

1. European Centre for Disease Prevention and Control (ECDC), Stockholm, Sweden

Citation style for this article:

Eurosurveillance editorial team. ECDC publishes the annual epidemiological report 2012. Euro Surveill. 2013;18(10):pii=20418. Available online: http://www. eurosurveillance.org/ViewArticle.aspx?Articleld $=20418$

Article published on 07 March 2013

The European Centre for Disease Prevention and Control (ECDC) released the sixth edition of its annual epidemiological report on communicable diseases in Europe [1]. It provides a comprehensive summary of surveillance data for 2010 and an analysis of the public health threats detected in 2011 through ECDC's routine epidemic intelligence.

This report analyses surveillance data on the key infectious diseases reported in the 27 European Union (EU) Member States and three European Economic Area (EEA) countries: Liechtenstein, Iceland and Norway.

Data for 2010 show that tuberculosis (TB) remains a common infection causing an important disease burden, with more than 70,000 cases notified annually in EU/EEA countries, although the reported overall TB rate continues to decline at about $4 \%$ per year.

During the 2010/11 influenza season, the pandemic virus (influenza $A\left(\mathrm{H}_{1} \mathrm{~N}_{1}\right)$ pdmog) continued to circulate widely and was the dominant type A virus in Europe, co-circulating with an increasing proportion of type $B$ viruses at the end of the season.

Human immonodeficiency virus (HIV) remains one of the major public health problems in EU/EEA countries, with a total number of around 28,000 new cases annually. In 2010, men who have sex with men represented the largest group of cases (38\%).

While Campylobacter infections are the most frequently reported gastrointestinal infections in all EU/ EEA countries, a number of other gastrointestinal infections such as brucellosis, trichinellosis, hepatitis $A$, are common only in certain countries and regions within the EU.
Vector-borne diseases remain a significant burden for the Member States, partly through infected travellers returning from countries where some of these diseases are endemic, in particular malaria, dengue fever and chikungunya.

Most vaccine-preventable diseases continued to show either a declining or stable trend in reported incidence. However, the number of measles cases reported in 2010 increased compared with the previous years. A total of 32,480 confirmed cases were reported in 2010 .

Antimicrobial resistance in Europe continued to increase, especially in Gram-negative pathogens, while the situation appeared more stable for Gram-positive pathogens.

In 2011, ECDC monitored 64 public health threats, which represent a 31\% decrease compared with 2010 . In 2011, threats were mainly related to food- and waterborne diseases (36\%), to diseases of environmental and zoonotic origin (31\%), to influenza (11\%) and others (antimicrobial resistance and healthcare-associated infections, sexually-transmitted infections, vaccinepreventable diseases or events not directly related to diseases).

References

1. European Centre for Disease Prevention and Control (ECDC). Annual epidemiological report. Reporting on 2010 surveillance data and 2011 epidemic intelligence data. Stockholm: ECDC. Mar 2013. Available from: http://www.ecdc.europa. eu/en/publications/Publications/Annual-EpidemiologicalReport-2012.pdf 